\title{
Real-Time Debriefing After Critical Events
}

\section{Exploring the Gap Between Principle and Reality}

\author{
Alexander F. Arriaga, MD, MPH, ScD ${ }^{a, b, c, *}$, Demian Szyld, MD, EdM ${ }^{d, e}$, \\ May C.M. Pian-Smith, MD, Ms ${ }^{e, f}$
}

\section{KEYWORDS}

- Critical event debriefing • Debriefing • Feedback • Patient safety

- Medical education $\bullet$ Crew/crisis resource management $\bullet$ Medical simulation

- Implementation science

\section{KEY POINTS}

- Debriefing after perioperative critical events potentially benefits the individual, team, environment, and overall health care system.

- In studies of actual critical events across medical disciplines, debriefing only takes place a fraction of the time.

- The implementation sciences, as well as recent implementation research pertaining to patient safety interventions, may provide insight toward closing the gap between principle and reality.

\section{INTRODUCTION}

Perioperative crises (eg, cardiac arrest, massive hemorrhage) are life-threatening events that can have a secondary impact on the providers themselves. ${ }^{1}$ Our understanding of the incidence of these crises is limited by variations in reporting requirements, definitions, and other factors. Based on safety reporting, available data suggest an incidence of 145 in 10,000 cases. ${ }^{2}$ With the global volume of surgery estimated at 313 million procedures per year, ${ }^{3,4}$ the burden of associated crises may be in the millions annually. ${ }^{5}$ Yet, these events can be rare at the level of individual providers,

\footnotetext{
a Department of Anesthesiology, Perioperative and Pain Medicine, Brigham and Women's Hospital, 75 Francis Street, Boston, MA 02115, USA; ${ }^{b}$ Ariadne Labs, Boston, MA, USA; ${ }^{c}$ Center for Surgery and Public Health, Boston, MA, USA; d Department of Emergency Medicine, Brigham and Women's Hospital, 75 Francis Street, Boston, MA 02115, USA; ${ }^{e}$ Center for Medical Simulation, Boston, MA, USA; ${ }^{f}$ Department of Anesthesia, Critical Care \& Pain Medicine, Massachusetts General Hospital, 55 Fruit Street, Boston, MA 02114, USA

* Corresponding author. Department of Anesthesiology, Perioperative and Pain Medicine, Brigham and Women's Hospital, 75 Francis Street, Boston, MA 02115.

E-mail address: aarriaga@post.harvard.edu

Twitter: @alexarriaga1234 (A.F.A.); @debriefmentor (D.S.)
} 
which only adds to their potential to induce stress, be complex to manage, and affect provider burnout and wellness. In a national survey of the impact of perioperative catastrophes on anesthesiologists, $84 \%$ of respondents noted they had been involved in at least 1 unanticipated death or serious injury over the course of their career, with $19 \%$ acknowledging they had never fully recovered. ${ }^{1}$ Further, these estimates of incidence do not include disruptive clinician behavior that undermines a culture of safety, ${ }^{6}$ critical communication breakdowns, ${ }^{7}$ events that become critical in the setting of a pandemic, ${ }^{8}$ and other critical events that have gained increased attention for their impact on providers.

Debriefing after critical events is supported by decades of literature in medicine and other high-stakes industries. ${ }^{9-16}$ Yet, in studies of actual clinical practice and critical events, a gap exists between principle and reality. In studies across medical disciplines, debriefing after critical events only takes place a fraction of the time. ${ }^{7,17,18}$

The purpose of this article is to explore this gap and facilitate the ability of readers to address the chasm. This article focuses on debriefing shortly after a critical event or the associated operation/procedure (ie, proximal debriefing; "hot" debriefing). ${ }^{19}$ For more on debriefing nomenclature in the context of the scope of this article, see Box 1. We seek to explore the growing suspicion" ${ }^{7,17,18}$ that "nothing debriefing" (ie, no debriefing) is taking place after countless perioperative crises internationally, and search for ways to improve this gap where indicated. This discussion will hopefully allow the reader to take a self-directed and locally customized approach toward best practices.

\section{PART I: THE POTENTIAL BENEFITS FROM DEBRIEFING}

Potential benefits of debriefing can affect individuals, cross-disciplinary groups and teams, and an entire system. Debriefing can both provide $360^{\circ}$ feedback to team members and address all of the residency core competencies from Accreditation Council for Graduate Medical Education, including medical knowledge, patient care, practice-based learning, interpersonal skills and communication, professionalism, and systems-based practice. ${ }^{13}$ Debriefing can facilitate mastery learning for events such as advanced cardiac life support and pediatric advanced life support. ${ }^{42}$ It plays a central role in experiential learning environments, such as medical simulation, with debriefing frameworks that have been designed and adapted for clinical environments. ${ }^{30,43-46}$ It has also been used as a vehicle to identify systems gaps and improve patient safety and quality. ${ }^{16}$ There are at least 2 reasons why debriefing critical events may have important benefits to the health care system. First, by listening to frontline clinicians, administrators and leaders can learn about the difference between "work as imagined" and "work as done." 47 Workarounds are very common in health care and can undermine safety processes. ${ }^{48}$ Second, organizational learning from celebrating successes is critical to sustaining resilience. Whereas errors and near misses can be reported to highlight safety threats, practices that contribute to safety are not frequently reported. These events can be deliberately solicited when teams debrief critical events and resuscitations. Leaders of health systems that implemented successful debriefing programs reported that "the debrief aims to identify and address flaws in the system and improve patient safety and system function." Debriefing leads to "addressing concerns that impacted the teams' ability to perform its job efficiently in addition to other issues related to improving performance. The fact that issues of equipment and process could be corrected, and the surgical team could experience the immediate benefits of participation, gave them a greater commitment to the process." 49 


\section{Box 1}

\section{Debriefing nomenclature in the context of the scope of this article}

The scope of this article is targeted at debriefing after critical events and the elusive gap that exists between principle and reality. This article is not meant to be a "how-to" for critical event debriefing or a review of different debriefing methods; there are existing texts that cover this. ${ }^{20,21}$ It is also not meant as a dedicated article on the implementation sciences, ${ }^{22-27}$ although some of this will be covered for its invaluable place in the conversation. In terms of nomenclature, we will draw some of our definitions from the American Heart Association Scientific Statement made by Cheng and colleagues:

Most literature blurs the line between feedback and debriefing ${ }^{28}$ Although this line remains indistinct, available definitions differentiate them. Here, we view data as a form of objective unprocessed information that makes up feedback. Thus, feedback is defined as information about the performance compared with a standard ${ }^{29}$ (eg, automatically generated data from simulators or devices that capture the quality of (PR). Debriefing is a reflective conversation about performance and may include processed select performance data (ie, feedback). ${ }^{30,31}$ Finally, performance refers to both taskwork and teamwork. ${ }^{32}$ Taskwork represents what the team does, such as adhering to a resuscitation algorithm, but also includes psychomotor skills, such as performing CPR or defibrillation; teamwork reflects how team members perform taskwork with each other. ${ }^{32}$

This article is focused on proximal, or "hot" debriefing, that is, debriefing at the point of care shortly after a critical event or the associated operation/procedure. ${ }^{19}$ This article is not specifically focused on routine debriefing after every single case, ${ }^{33,34}$ although this broader strategy would invariably include cases where there was a critical event. Indeed, there is evidence that interventions that involve routine debriefing after every case can improve patient and other outcomes if successfully implemented. ${ }^{35-38}$ Salient research and implementation lessons from routine debriefing is discussed where appropriate, while attempting to keep critical event debriefing at the center of this review.

This article is not exclusive to critical incident stress debriefing, which is mentioned as a type of debriefing after critical events and has a valuable role in the topic of debriefing overall. ${ }^{12,39,40}$ An entire article can be written exploring the foundations and theories of different debriefing approaches, and there is growing literature on the considerable commonality that now exists between feedback and debriefing, with a call for future work regarding the relevance of integrating these concepts where appropriate. ${ }^{41}$

Data from Refs. ${ }^{12,19-41}$

Another key benefit of debriefing is its ability to identify and potentially mitigate the negative impact that critical events can have on health care providers. In a national survey of anesthesiologists regarding perioperative catastrophic events, more than $70 \%$ of those reporting a "most memorable" perioperative catastrophe experienced guilt, anxiety, and reliving of the event; $88 \%$ required time to recover emotionally and $19 \%$ noted they never fully recovered. Overall, $89 \%$ of respondents felt that debriefing with the entire operating room (OR) team would be helpful to providers in the future, and $68 \%$ felt the resource should be a standard operating procedure. ${ }^{1}$ In a separate survey study of consultant anesthesiologists in Australia, who were presented with a hypothetical crisis scenario, the majority agreed or strongly agreed that there should be a formal strategy for anesthesiologists to deal with the aftermath, and $83 \%$ agreed or strongly agreed that "debriefing the OR team immediately after a perioperative death is advisable." 12 Similar results were found in a survey study of anesthesiologists in Canada regarding their experience with unanticipated perioperative deaths. ${ }^{50}$ 
These findings are particularly important in this era of attention to provider wellbeing and burnout. ${ }^{51-53}$ Clinicians are already at the forefront of absorbing the hazards of crisis events, sometimes with the label of "hero," as they protect patients from an imperfect system. ${ }^{54,55}$ During the coronavirus disease-19 (COVID-19) pandemic, there were 18 anesthesiologists and 2 anesthesia nurses in China who became known as the "coronavirus intubation team racing against death," who performed nearly 50 intubations over 8 days for patients with severe COVID-19. ${ }^{8}$ In the setting of this and other events, the Chinese Society of Anesthesiology and the Chinese Association of Anesthesiologists jointly established a platform for free mental health advice to all anesthesia providers ${ }^{8}$; one can envision the role debriefing can play in this process. Despite all the potential benefits from debriefing, it is acknowledged that health care providers should not be forced to debrief, because some people may recover best with solitude and isolation, ${ }^{12}$ and more involved forms of debriefing (such as critical incident stress debriefing) ${ }^{39,40}$ could have unintended iatrogenic effects. ${ }^{56}$ Overall, the reported potential benefits of debriefing after critical events have been largely positive across an international sample of providers.

\section{PART II: THE LANDSCAPE AND SCARCITY OF THIS PRACTICE AFTER ACTUAL CRITICAL EVENTS}

Despite the long history of debriefing in medicine and other high-stakes industries, there is growing evidence that the rate of debriefing after perioperative crises is far from $100 \%$. Our understanding is hindered in part owing to the paucity of research studying actual critical events (vs simulated or hypothetical events). This likely stems from the unpredictable, often sudden, and relatively infrequent occurrence of perioperative crises compared with overall surgical and procedural volumes. Nevertheless, even survey research can yield great insight. In the survey study of Canadian anesthesiologists registered with the College of Physicians and Surgeons of Alberta (ie, not specific to trainees) regarding unanticipated perioperative deaths, only $14 \%$ of those reporting an unanticipated perioperative death participated in an OR debriefing or other immediate process. ${ }^{50}$ No specific reason for this lack of debriefing was provided, although themes from free-text participant comments called for formal policies for support of OR team members and encouragement for support that was individualized to specific needs.

This phenomenon is not specific to anesthesiology or even the perioperative space. A brief summary of selected literature can be found in Box 2. There is a common finding that "hot" debriefs in clinical settings are infrequent, and the barriers noted in studies and other publications (including "too many urgent patient care issues," lack of trained debriefing facilitators [which may influence willingness to facilitate/ debrief], fear of judgment from colleagues, discomfort regarding the event, lack of administrative support, and overall buy-in) ${ }^{13,18,57,58}$ may resonate with members of a perioperative team who struggle with constraints of production pressure, coupled with limited time and space, in busy surgical and procedural areas.

In addition to these survey studies, our understanding is enhanced by mixedmethods research that includes semistructured interviews of participants shortly after actual critical events. In a study of critical events experienced by anesthesiology residents at a large academic medical center over a 1 -year period, ${ }^{7}$ only $49 \%$ of the events were associated with at least some bare minimum components of a proximal debriefing that included the study participant. Only $39 \%$ of events occurred in the OR (ie, main OR locations excluding obstetric ORs and non-OR anesthesia locations), which speaks to both the rapid expansion of non-OR anesthesia, as well as the 


\section{Box 2}

Lessons from selected medical literature not specific to anesthesiology on the landscape and scarcity of debriefing after actual critical events

- A national survey of pediatric emergency medicine fellows regarding critically ill children in the emergency department (ED) showed that $99 \%$ of respondents had participated in medical resuscitations during their fellowship, yet more than $30 \%$ indicated that they had never participated in a debriefing session afterward; the majority estimated that postresuscitation debriefing in the ED took place $50 \%$ or less of the time. Although the reasons for this were unclear, $88 \%$ of respondents reported no formal teaching on how to debrief, and $87 \%$ noted that their fellowship program did not have a structured format for debriefing. ${ }^{18}$

- A survey of staff from Canadian pediatric EDs (nurses, fellows, and attending physicians) revealed that $52.5 \%$ of respondents indicated that debriefing after real resuscitations occurred less than $25 \%$ of the time, and $63 \%$ had no previous training in debriefing. More than $90 \%$ of respondents indicated workload and time shortages as debriefing barriers. ${ }^{58}$

- In a study on the implementation of a debriefing tool for emergent resuscitations in a pediatric ED, there was a $26 \%$ debriefing rate after the critical events of interest (cardiopulmonary resuscitation, intubation, and/or defibrillation), and "too many urgent patient care issues" was identified as a theme in cases not debriefed. ${ }^{57}$

- In a survey of resuscitation training officers (physicians [house officers (including in anesthesia) and registrars], nurses, and other team members responding to in-hospital cardiac arrest) across the United Kingdom, less than $8 \%$ of respondents said they completed a formal debrief after a cardiac arrest. The reasons for this were again unclear, although the majority of respondents noted that debrief sessions were either offered but not taken up, or were very informal, often limited to a few members of team. ${ }^{59}$

- In a survey study of Canadian internal medicine residents, only $5.9 \%$ of cardiac arrest teams reported receiving postevent debriefing and only $1.3 \%$ reported getting performance feedback. Although the respondents did not report a reason, more than $85 \%$ reported that postcardiac arrest debriefing would indeed be effective or very effective for improving their skills and confidence. ${ }^{17}$

Data from Refs. ${ }^{17,18,57-59}$

ubiquitous presence of anesthesia providers throughout the health system. For any scalable intervention to improve critical event debriefing for an entire team, the anesthesia provider could be in a unique position to spread the intervention across the OR, non-OR anesthesia locations, intensive care units, labor and delivery, code teams, trauma alert teams, and other areas. The authors also studied critical events that involved disruptive behavior and critical communication breakdowns; they found that the presence of a critical communication breakdown was significantly associated with the event not being debriefed (illustrative vignettes of these breakdowns are shown in Table 1). This finding supports the notion that barriers to debriefing are not just related to time, space, resources, training, production pressure, or even belief in the value of debriefing overall. There may be social and interpersonal factors at play regarding whether proximal debriefing is viable, or at the very least whether it is likely to happen easily.

This mixed-methods study was followed up with a qualitative study that further explored the interviews with anesthesia residents after actual critical events. ${ }^{60}$ The interviews revealed that debriefing for the residents, in the setting of real events, was considered part of a multistage process that included internal dialogue, event documentation (as a component of reconstructing what happened), and lessons they felt they learned (not necessarily in this order or with distinct borders). In each stage of 


\begin{tabular}{|c|c|c|}
\hline Category & Description & Illustrative Vignette \\
\hline Audience failure & $\begin{array}{l}\text { Key person missing from a } \\
\text { critical Conversation }\end{array}$ & $\begin{array}{l}\text { "Profound desaturation after resident } \\
\text { extubated patient at the end of a case. } \\
\text { A second on-call anesthesia resident } \\
\text { incidentally was also present for } \\
\text { extubation ... neither of us had a free } \\
\text { hand. And I think at some point, I don't } \\
\text { remember exactly when it was, we } \\
\text { asked the circulator, can you please call } \\
\text { our attending. And she couldn't reach } \\
\text { our attending. She called the wrong } \\
\text { attending." }\end{array}$ \\
\hline Occasion failure & $\begin{array}{l}\text { A key discussion that became } \\
\text { futile to poor timing or a } \\
\text { lack of communication of } \\
\text { a key piece of clinical } \\
\text { information during the } \\
\text { event }\end{array}$ & $\begin{array}{l}\text { A critically ill patient scheduled for an } \\
\text { elective case transported directly to the } \\
\text { OR without communication between } \\
\text { relevant parties involved. No tracing on } \\
\text { the arterial line (unclear timing of this); } \\
\text { massive pulmonary embolism } \\
\text { suspected. }\end{array}$ \\
\hline Content failure & $\begin{array}{l}\text { Insufficient or inaccurate } \\
\text { information regarding } \\
\text { critical details }\end{array}$ & $\begin{array}{l}\text { Elective case canceled in preoperative } \\
\text { holding area after } 3 \text { hours of } \\
\text { attempted coordination and data } \\
\text { gathering involving an adult patient } \\
\text { with congenital heart disease }\end{array}$ \\
\hline Purpose failure & $\begin{array}{l}\text { Failure to resolve a critical } \\
\text { issue that was discussed, } \\
\text { or discontent/ } \\
\text { disagreement with } \\
\text { another clinician } \\
\text { regarding a critical issue }\end{array}$ & $\begin{array}{l}\text { Strong disagreement between nurse and } \\
\text { anesthesia resident regarding the } \\
\text { administration of naloxone during a } \\
\text { request for intubation of a patient in } \\
\text { the hospital ward. Two additional } \\
\text { requests for intubation of patients in } \\
\text { the hospital occurred right after this } \\
\text { incident. Never was addressed. }\end{array}$ \\
\hline Systems failure & $\begin{array}{l}\text { Lapse in communication at } \\
\text { the organizational level }\end{array}$ & $\begin{array}{l}\text { Obstetric emergency ("level 1") called on } \\
\text { the labor and delivery floor; pagers } \\
\text { were down. This led to a delay in the } \\
\text { discussion between the anesthesia and } \\
\text { obstetric teams regarding critical } \\
\text { information. }\end{array}$ \\
\hline
\end{tabular}

From Arriaga AF, Sweeney RE, Clapp JT, et al. Failure to Debrief after Critical Events in Anesthesia Is Associated with Failures in Communication during the Event. Anesthesiology 2019;130(6):10391048; Table 2, p.1043; with permission.

this process, there were residents who were self-negotiating their perceived reputation, affective response, and extent to which they internally felt culpable for what had happened. One resident being interviewed after a critical event pondered "if things would have gone differently" if they themselves had been better prepared. Another resident intentionally avoided discussing the critical event out of fear that colleagues may judge them: "Why is this incompetent resident asking so many questions right now? ...especially since I was in the mindset of blaming myself for the situation." In the medical literature, debriefing is noted for its ability to mitigate shame and blame and embrace patient safety and the medical simulation principle of respecting a 
predefined basic assumption regarding the ability and engagement of participants (a popular basic assumption in simulation and debriefing is that, "We believe that everyone participating in this simulation is intelligent, capable, cares about doing their best, and wants to improve"). ${ }^{21,27,61}$ Despite an abundance of medical literature supporting the ability of debriefing to directly address these resident concerns of reputation, culpability, and affective response, the rate of debriefing after critical events in this study was only $49 \%$, which (based on the literature) may even overestimate how frequently debriefing is taking place more broadly. This finding supports the cultural barriers that have been noted by others less directly via needs assessment surveys and editorials. ${ }^{13,58}$ These issues go well beyond getting leadership to buy-in; obtaining time, space, and resources; and addressing production pressure. To truly close this gap, there will likely need to be more research that involves lessons from both medical simulation and actual events at the point of care. Some of this may involve getting a better understanding of what providers are actually learning and/or changing, at the point of care, as the result of a proximal debriefing. In the words of the teamwork and patient safety experts Salas and colleagues, ${ }^{27}$ "Even if this [debriefing, especially after critical events] lasts for as little as 3 minutes, it is important to be able to discuss the relevant event(s) and the observed teamwork behaviors in an environment that is, safe from administrative oversight where the focus must be on gaining information, understanding, and insight." Perhaps the synthesis of the gap between the medical literature and reality is best summarized by an editorial by Pian-Smith and Cooper (Box 3).

\section{PART III: THE BRIDGE BETWEEN PRINCIPLE AND REALITY: STRATEGIES TO OFFER OPPORTUNITIES FOR REFLECTION ON ACTUAL CRITICAL EVENTS The Implementation Sciences}

The implementation sciences represent an important field of study to leverage when introducing real-time debriefing into actual clinical practice. As nomenclature, we provide some terminology offered by Rapport and colleagues (Box 4).

Rapport has placed several of these concepts into a schematic, showing an interconnected feedback loop that can be created across 5 surrounding categories (Fig. 1). There is a large range of literature available relevant to local implementation of a patient safety intervention, including introductory overviews of the field ${ }^{66}$; systematic and literature reviews ${ }^{25,67}$; studies that work toward common definitions, frameworks, and categories ${ }^{68,69}$; and step-by-step implementation checklists and processes. ${ }^{70,71}$ There are also works specific to patient safety interventions and/or

\footnotetext{
Box 3

Excerpt from 2019 Editorial by Pian-Smith and Cooper regarding debriefing after real critical events $^{62}$
}

We strongly believe that routine debriefing after all critical events is the right thing to do. However, we acknowledge that there is not good evidence or experience for how best to do it. There is evidence that our debriefings, as they stand now, are not ideal: participants can be left feeling more personally responsible, blamed, depressed, and fearful. ${ }^{1}$ We have much to learn about how to make the debriefs safe, effective, and practical.... These and other questions can best be answered with research on this topic, perhaps much of it in the natural environment during real debriefings and also via simulation.

Data from Refs. 1,62 


\section{Box 4 \\ Nomenclature from the implementation sciences (from Rapport and colleagues) ${ }^{26}$}

Implementation science, dissemination and implementation (D\&l), ${ }^{63}$ evidence-based interventional dissemination, ${ }^{64}$ and implementation research, ${ }^{65}$ is a basket of terms that refers to the application of effective and evidence-based interventions, in targeted settings, to improve the health and well-being of specific population groups. Implementation science is the scientific study of methods that take findings into practice, while 'effective implementation' refers to the process whereby an actionable plan is appropriately and successfully executed.

Data from Refs. ${ }^{26,63-65}$

debriefing, not all of which are exclusive to the implementation sciences, where lessons salient to implementing critical event debriefing can be gathered. ${ }^{22-24,27,72}$ This literature, some of which is reviewed elsewhere in this article, should be considered a foundation toward the development of an implementation plan.

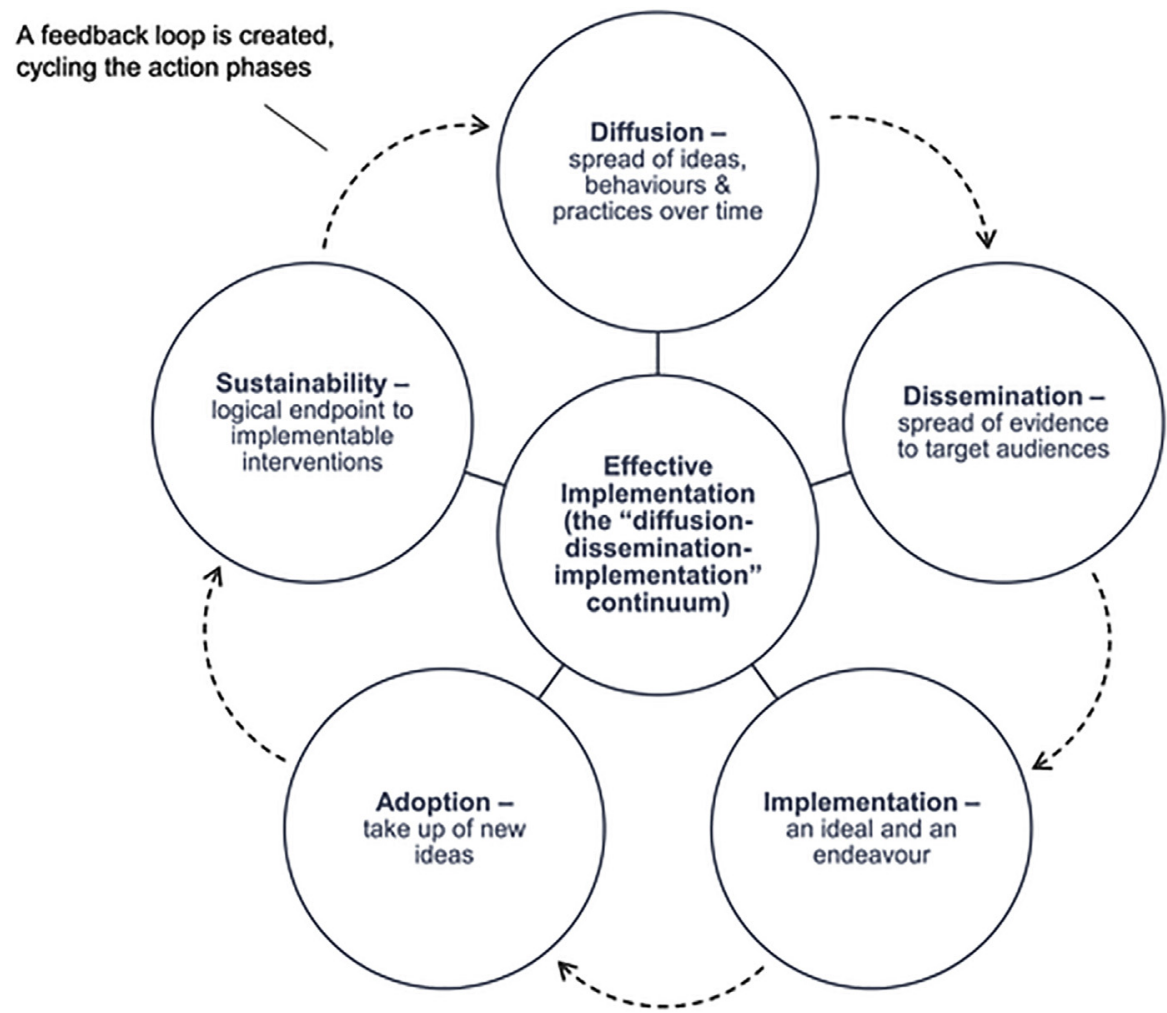

Fig. 1. Five foundational categories of implementation science. ${ }^{26}$ (From Rapport F, ClayWilliams R, Churruca K, et al. The struggle of translating science into action: Foundational concepts of implementation science. J Eval Clin Pract 2018;24(1):117-126. Figure 1, p. 119. With permission.) 
The literature on implementation sciences (some of which is not necessarily specific to medicine) offers tremendous insight toward the development of a roadmap to implement change in the field of critical event debriefing. In 2012, Meyers and colleagues ${ }^{70}$ described the critical steps of implementation as part of a quality improvement framework comprising 14 interrelated steps across 4 phases (Fig. 2). One can imagine putting the contents of Fig. 2 on a large dry-erase board as a template to map out a strategy specific to a debriefing program customized to one's own institution. It is hard to argue against the value of conducting a needs assessment, determining available resources, and getting buy-in from key stakeholders. Several of these strategies have also been associated with successful implementation of other patient safety interventions, including tools for debriefing. ${ }^{23,24,57}$ The essential role of hospital leaders and resources was emphasized in a review by Salas and colleagues $^{27}$ on a set of evidence-based best practices and tips for debriefing medical teams.

In a systematic review of targeted literature at the intersection of implementation science and quality/patient safety, Braithwaite and colleagues ${ }^{25}$ derived 8 success factors of implementation (Box 5). Although the factors in Box 5 are more overarching and may require more heavy lifting than the schematic approach in Fig. 2, they may offer greater potential for longer term planning, rapid cycle improvements, and sustainability. The Consolidated Framework for Implementation Research, the Expert Recommendation for Implementing Change, and Gagliardi and colleagues ${ }^{71}$ publications have offered implementation strategy typologies, terms, checklists and/or definitions for those seeking a much more comprehensive list to consider for applicability (such as whether one is at the stage of broad and/or global implementation, such as mass media campaigns and creating debriefing tools in different languages). ${ }^{66,68,69}$

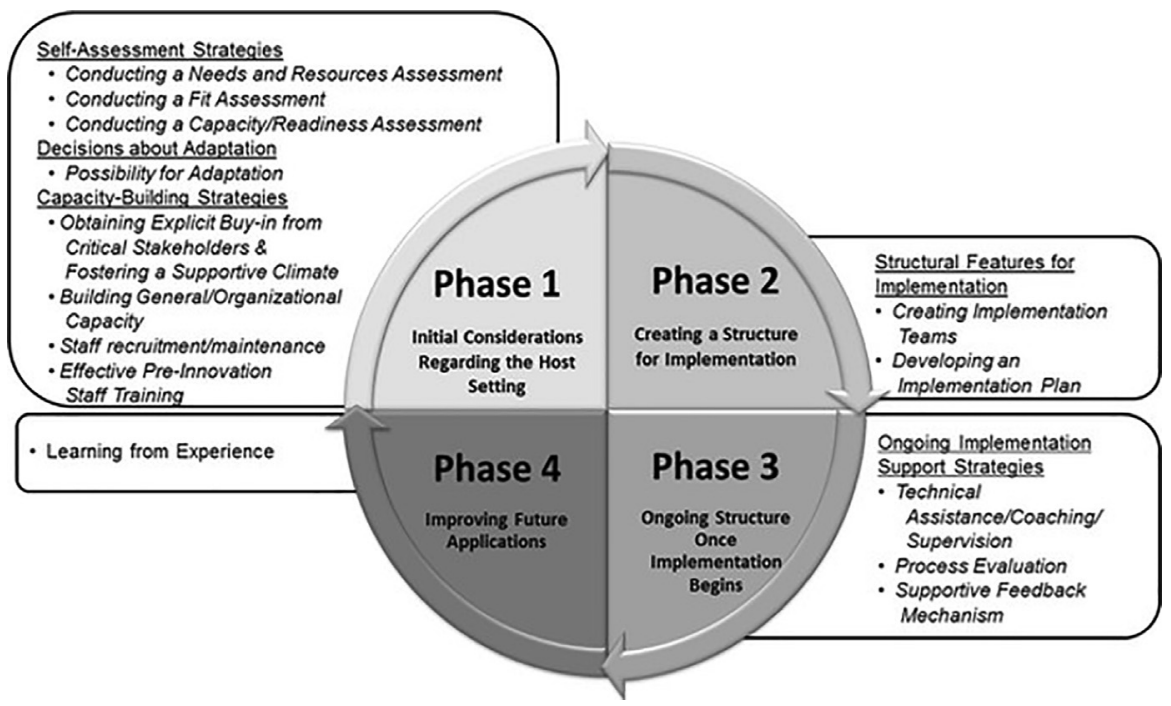

Fig. 2. Critical steps of implementation as part of a quality improvement framework. ${ }^{70}$ (From Meyers DC, Durlak JA, Wandersman A. The quality implementation framework: a synthesis of critical steps in the implementation process. Am J Community Psychol 2012;50(34):462-480. Figure 2, p. 475; with permission.) 


\section{Box 5}

Success factors for implementation to improve care quality and patient safety (Braithwaite and colleagues ${ }^{25}$ )

1. Preparing for change (planning from the organization and associated staff).

2. Assessing capacity for implementation, both in terms of people (ie, presence of individuals skilled in the initiative being implemented) and setting (see factor 3 ).

3. Setting (ie, a setting that is capable of and receptive to change).

4. Choosing the right type of implementation (examples include guidelines, reminders, alerts, checklists, and/or cultural changes).

5. Obtaining resources needed for implementation.

6. Leverage (ie, harnessing key individuals, such as opinion leaders, champions, and change agents).

7. Desirable implementation enabling features (a mosaic of factors including communication, incentives, feedback, and customization to organization/staff needs).

8. Sustainability (including a commitment for ongoing support at a managerial level).

Data from Braithwaite J, Marks D, Taylor N. Harnessing implementation science to improve care quality and patient safety: a systematic review of targeted literature. Int J Qual Health Care 2014;26(3):321-329.

\section{LESSONS FROM THE IMPLEMENTATION OF CRISIS CHECKLISTS AND EMERGENCY MANUALS}

There are patient safety tools with associated implementation research, namely, crisis checklists and emergency manuals, that have a natural and logical connection to critical event debriefing given their role to aid in the management of critical events. Crisis checklists, emergency manuals, and other cognitive aids for anesthesia crisis management have existed for decades, ${ }^{73-77}$ and they have an even broader reach in their use in aviation and other high-stakes industries. ${ }^{78}$ The emergency manual produced by the Stanford Anesthesia Cognitive Aid Group has 2 dedicated pages devoted to key points in crisis resource management, ${ }^{79}$ and the book by Gaba and colleagues ${ }^{73}$ on crisis management in anesthesiology (which catalogs the management of 99 critical events in anesthesiology) has a dedicated article on debriefing. Goldhaber-Fiebert and Howard $^{80}$ popularized 4 vital elements for widespread development and implementation of emergency manuals (which may be valuable in extending these resources to formal debriefing tools): create, familiarize, use, and integrate. In 2013, a simulationbased randomized controlled trial of surgical crisis checklists was published in the New England Journal of Medicine reporting that use of crisis checklists was associated with nearly a $75 \%$ reduction in failure to adhere to critical steps in management. ${ }^{81}$ The Emergency Manuals Implementation Collaborative has subsequently been created to foster the adoption and effective use of emergency manuals to enhance patient safety. ${ }^{82}$ We provide a brief paragraph elsewhere in this article on specific suggestions at the intersection of crisis checklists and emergency manuals and critical event debriefing. For more information on cognitive aids in the management of critical events and other salient lessons for implementation, see the publication by Hannenberg, ${ }^{83}$ as well as the OR Emergency Checklist Implementation Toolkit. ${ }^{84}$

Building on the thought that perioperative critical events could trigger a debriefing, an institution, department and/or division can identify the specific types of events that should prompt a member of the team to offer a debriefing, or at the very least to screen 


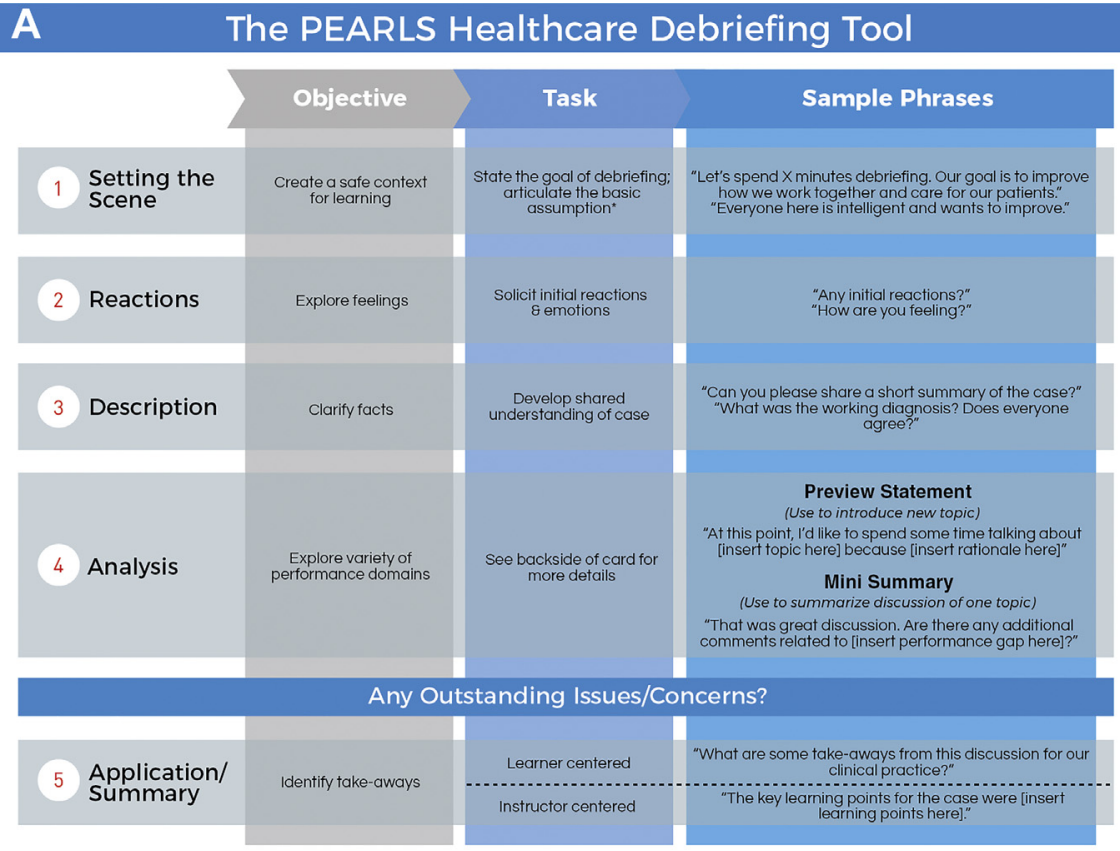

\section{B The Analysis Phase}

\section{Performance Domains}

The analysis phase can be used to explore a variety of performance domains:

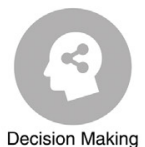

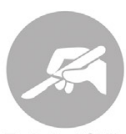

Technical Skills

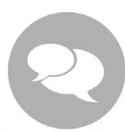

Communication

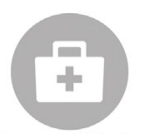

Resource Utilization

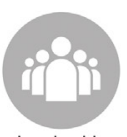

Leadership

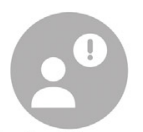

Situational Awareness

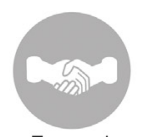

Teamwork

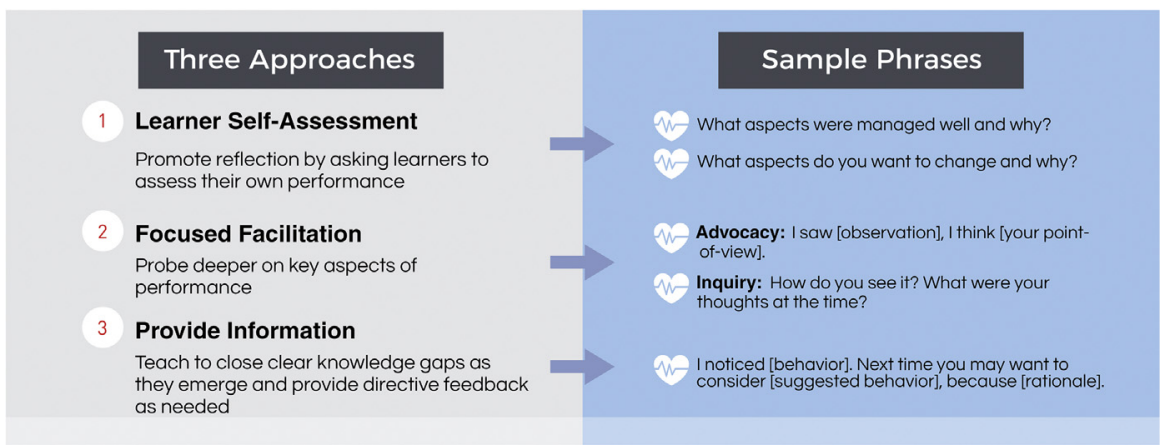

Fig. 3. The PEARLS (promoting excellence and reflective learning in simulation) health care debriefing tool. ${ }^{44}(A)$ : Front; $(B)$ : Back. (From Bajaj K, Meguerdichian M, Thoma B, et al. The PEARLS Healthcare Debriefing Tool. Acad Med 2018;93(2):336. Page 336; with permission.) 
for matters that should be addressed before the next case; provide psychological first aid and/or improve awareness of local peer support and employee assistance resources; and assess if team members are able to continue providing care. Similar to how damage control surgery or resuscitation can have a set of goals, ${ }^{85}$ "hot" debriefing may provide an opportunity to address certain issues acutely salient to the critical event, the next case, and/or rest of the day or night. The strategy of defining critical events to prompt at least brief communication and debriefing has been described in both the fields of emergency medicine and surgery, with advice to consider starting with events that are most common and/or relevant to staff. ${ }^{20,86}$ Based on more recent work studying debriefing after real critical events in anesthesia, one may also want to consider categories for disruptive behavior that undermines a culture of safety, ${ }^{6}$ critical communication breakdowns, ${ }^{86-89}$ and any event for which an individual specifically requests a debriefing. ${ }^{7}$ There is also emerging research to suggest synergy between the implementation of crisis checklists and emergency manuals and critical event debriefing. In a cross-sectional study of US hospitals and ambulatory surgery centers, more successful implementation of crisis checklists and emergency manuals was associated with the use of these tools to aid in debriefing after a critical event. ${ }^{23}$ In an institutional case report of implementing emergency manuals, teams were encouraged to debrief using the emergency manuals when events occurred. ${ }^{24}$

\section{Specific Debriefing Tools and Training Programs}

We purposefully leave this section brief, because the scope of this article is not to prescribe a specific debriefing method or give a "how-to" for debriefing. It would be the

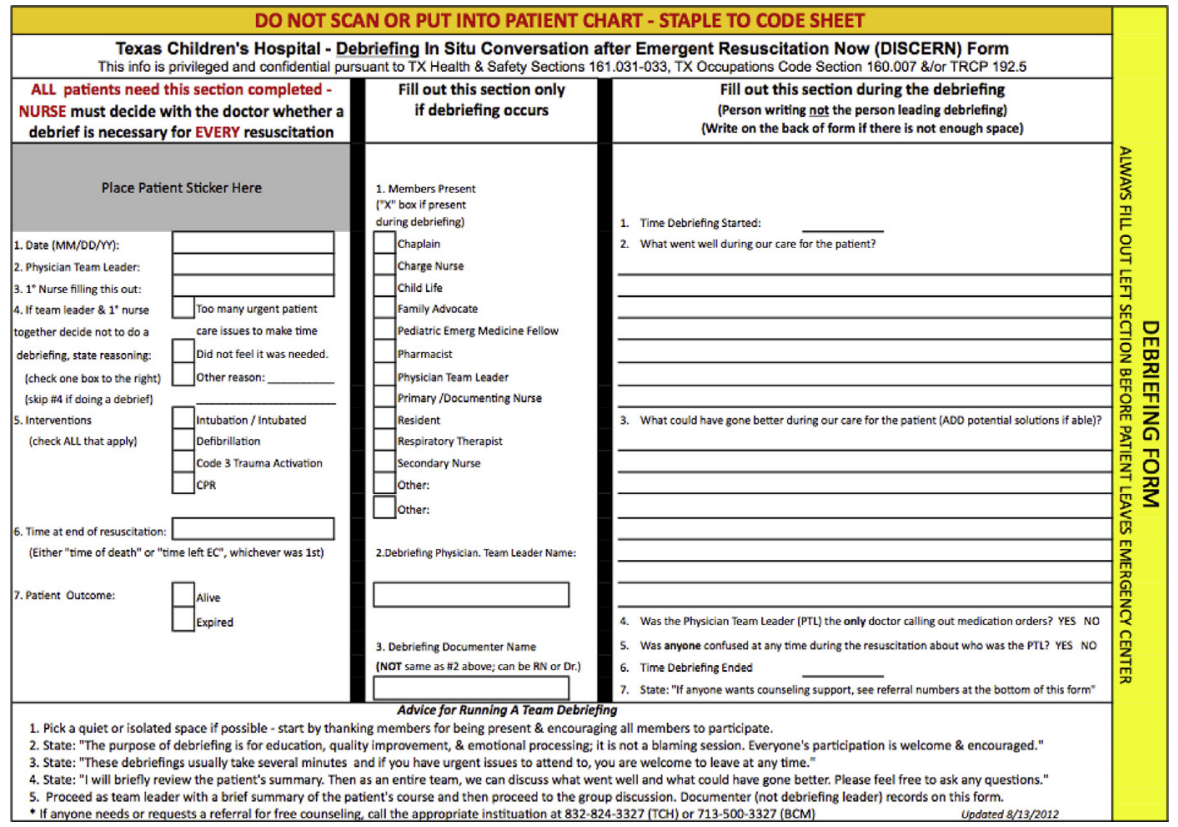

Fig. 4. The DISCERN (debriefing in situ conversation after emergent resuscitation) tool. ${ }^{57}$ (From Mullan PC, Wuestner E, Kerr TD, et al. Implementation of an in situ qualitative debriefing tool for resuscitations. Resuscitation 2013;84(7):946-951. Figure 1, p. 948; with permission.) 


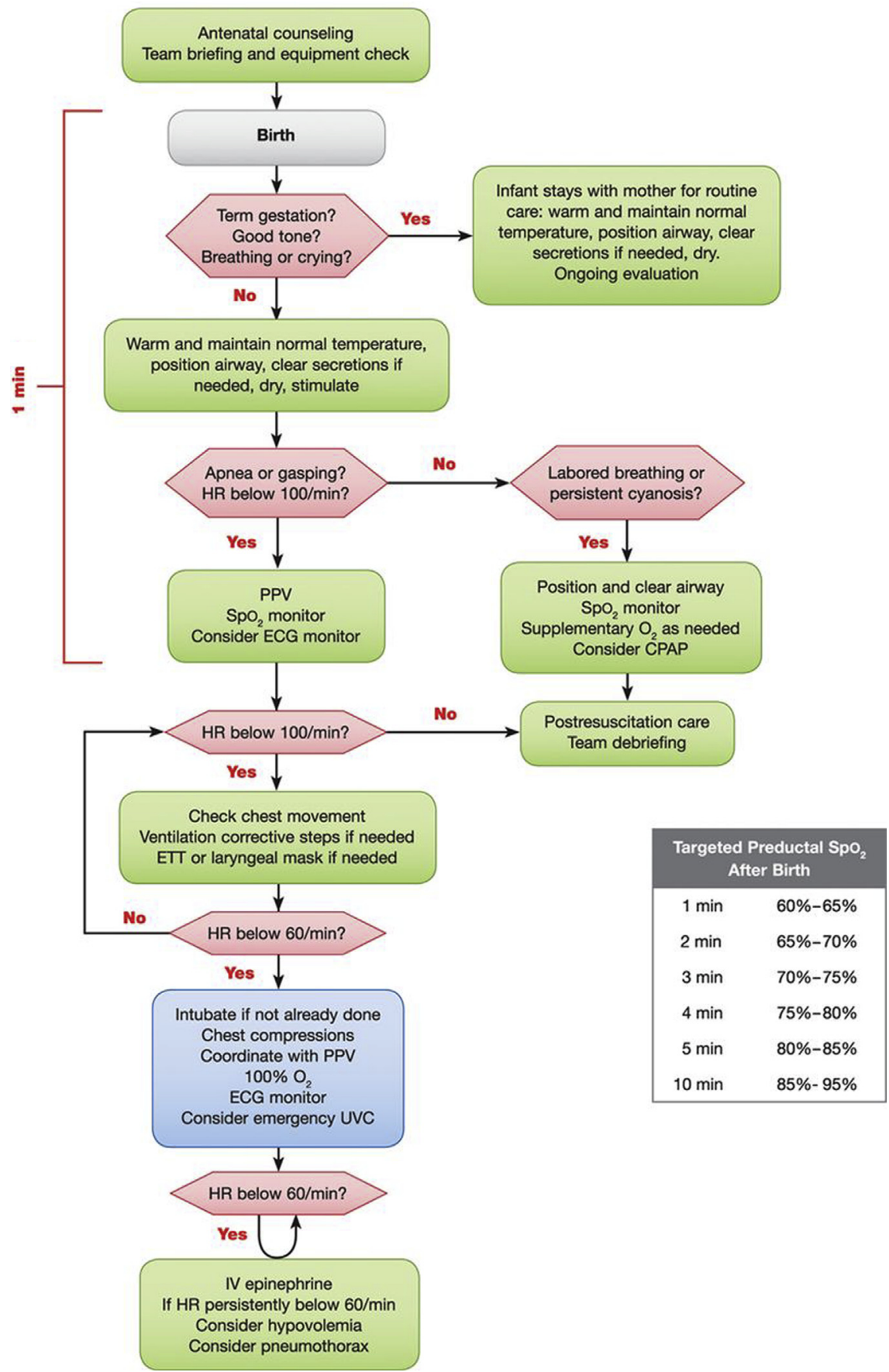

Fig. 5. Neonatal resuscitation algorithm (American Heart Association. 2015 update). ${ }^{98}$ (Reprinted with permission from Wyckoff MH, Aziz K, Escobedo MB, et al. Part 13: Neonatal Resuscitation: 2015 American Heart Association Guidelines Update for Cardiopulmonary Resuscitation and Emergency Cardiovascular Care. Circulation 2015;132(18 Suppl 2):S543560. Figure 1, page S544. (@ 2015 American Heart Association, Inc.) 
subject of an entire article, chapter, and/or series to thoroughly review this. Nevertheless, given the importance of this topic, we provide some literature to allow the reader to customize existing debriefing tools and resources into locally relevant versions. An action card containing items to consider after a real critical event (including debriefing) has been developed based on thousands of incident reports from anesthetists in Australia and New Zealand. ${ }^{90}$ Debriefing courses, based on decades of experience and thousands of debriefings of health care simulation, are offered by various programs, for example, the Center for Medical Simulation. ${ }^{91,92}$

Alternatives to traditional high-fidelity simulation have also been explored. Widespread scaling and/or local customization of debriefing programs can invariably involve barriers referred by Delisle and colleagues ${ }^{93}$ as the "Three Ts" (training, technology, and time). These barriers may be particularly relevant for areas with limited access to simulation centers and/or specific needs to match local resources. Delisle and Hannenberg review options including telesimulation and teledebriefing, 2 modalities that may become increasingly relevant, even for high-fidelity simulation centers, in the COVID-19 era and beyond. For those seeking more summative information, a review article on different debriefing methods, as well as a conceptual framework for the development of debriefing skills, have been published, and both provide invaluable content to inform educational practice. ${ }^{21,94}$

There are also specific debriefing tools and other resources. The Promoting Excellence And Reflective Learning approach to debriefing has been developed for simulation-based education and adapted in the form of a health care debriefing tool/cognitive aid (Fig. 3; this tool has since been translated into multiple languages; as of this publication, the latest version is available at debrief2learn.org). ${ }^{43,44,95}$ Specific to point-of-care debriefing after emergent resuscitations, the Debriefing In Situ Conversation after Emergent Resuscitation Now tool has been developed, and its implementation has been tested in an emergency department setting (Fig. 4). ${ }^{57}$ There are many approaches to debriefing and no comparative studies to suggest that one may be better than another. ${ }^{21}$ Kessler and colleagues ${ }^{20}$ describe that although physicians are the most common debriefer, social workers and other clinicians can also debrief. Debriefing after clinical events may be led by nurses with minimal prior training. ${ }^{96}$ The TALK debrief (https://www.talkdebrief.org), funded by the European Union, is trying to lower barriers by decreasing the need to train facilitators and encouraging all health care personnel to begin a debriefing. We recommend individuals and institutions select 1 approach to debriefing that they find useful and focus on mastery by, for example, developing a peer coaching approach. ${ }^{97}$

\section{SUMMARY}

Debriefing after perioperative critical events potentially benefits the individual, team, environment, and overall health care system. At the point of care, there is still a noticeable gap to making this ritual a reliable occurrence. Future work will need to be done, both via medical simulation and actual critical events, to learn how to make point-ofcare debriefing safe, effective, and practical, ${ }^{62}$ and how to achieve broad implementation, improvement and sustainability. Debriefing deserves the same level of importance as other aspects of managing a critical event. In the American Heart Association Guidelines for Neonatal Resuscitation, "team debriefing" is a key step highlighted in their popular cognitive aid (Fig. 5)..$^{98}$ The American Heart Association scientific statement on resuscitation education science places prominent emphasis on feedback and debriefing. ${ }^{15}$ As the popularity grows for resuscitation algorithms specific to anesthesiologists and perioperative teams, ${ }^{76}$ perioperative providers and 
procedure teams can have broad influence on reshaping how the aftermath of critical events are handled at the point of care.

\section{ACKNOWLEDGMENTS}

Supported by a grant from the Anesthesia Patient Safety Foundation (APSF) and the Foundation for Anesthesia Education and Research (FAER). The views expressed in this article are those of the authors and do not necessarily represent the official vies of APSF or FAER.

\section{DISCLOSURE}

A.F. Arriaga is the recipient of a mentored research training grant from the Anesthesia Patient Safety Foundation and the Foundation for Anesthesia Education and Research. He is the recipient of a Career Development Award from the Center for Diversity and Inclusion of the Brigham and Women's Hospital. He is a member of the Patient Safety Editorial Board for the American Society of Anesthesiologists and Question Editor for the American Board of Anesthesiology, where he receives a stipend for work that is otherwise done in a volunteer capacity. D. Szyld is the Senior Director for the Simulation Education Program of the Center for Medical Simulation. The Center for Medical Simulation provides courses and consulting to individuals and institutions in the areas of teamwork, crisis resource management, simulation-based education and debriefing. M.C.M. Pian-Smith is on the Board of Directors of both the Anesthesia Patient Safety Foundation and the Foundation for Anesthesia Education and Research. She is Adjunct Faculty for the Center for Medical Simulation. The Center for Medical Simulation provides courses and consulting to individuals and institutions in the areas of teamwork, crisis resource management, simulationbased education and debriefing.

\section{REFERENCES}

1. Gazoni FM, Amato PE, Malik ZM, et al. The impact of perioperative catastrophes on anesthesiologists: results of a national survey. Anesth Analg 2012;114(3): 596-603.

2. Charuluxananan S, Punjasawadwong Y, Suraseranivongse S, et al. The Thai Anesthesia Incidents Study (THAl Study) of anesthetic outcomes: II. Anesthetic profiles and adverse events. J Med Assoc Thai 2005;88(Suppl 7):S14-29.

3. Weiser TG, Regenbogen SE, Thompson KD, et al. An estimation of the global volume of surgery: a modelling strategy based on available data. Lancet 2008; 372(9633): 139-44.

4. Weiser TG, Haynes AB, Molina G, et al. Size and distribution of the global volume of surgery in 2012. Bull World Health Organ 2016;94(3):201-209F.

5. Ziewacz JE, Arriaga AF, Bader AM, et al. Crisis checklists for the operating room: development and pilot testing. J Am Coll Surg 2011;213(2):212-7.e10.

6. Sanchez LT. Disruptive behaviors among physicians. JAMA 2014;312(21): 2209-10.

7. Arriaga AF, Sweeney RE, Clapp JT, et al. Failure to Debrief after Critical Events in Anesthesia Is Associated with Failures in Communication during the Event. Anesthesiology 2019;130(6):1039-48.

8. Zhang HF, Bo LL, Lin $Y$, et al. Response of Chinese Anesthesiologists to the COVID-19 Outbreak. Anesthesiology 2020;132(6):1333-8. 
9. Sawyer TL, Deering S. Adaptation of the US Army's After-Action Review for simulation debriefing in healthcare. Simul Healthc 2013;8(6):388-97.

10. Brett-Fleegler M, Rudolph J, Eppich W, et al. Debriefing assessment for simulation in healthcare: development and psychometric properties. Simul Healthc 2012;7(5):288-94.

11. Mackinnon R, Gough S. What can we learn about debriefing from other high-risk/ high-stakes industries? Cureus 2014;6(4):e174.

12. Heard GC, Thomas RD, Sanderson PM. In the aftermath: attitudes of anesthesiologists to supportive strategies after an unexpected intraoperative patient death. Anesth Analg 2016;122(5):1614-24.

13. Mullan PC, Kessler DO, Cheng A. Educational opportunities with postevent debriefing. JAMA 2014;312(22):2333-4.

14. Minehart RD, Rudolph J, Pian-Smith MC, et al. Improving faculty feedback to resident trainees during a simulated case: a randomized, controlled trial of an educational intervention. Anesthesiology 2014;120(1):160-71.

15. Cheng A, Nadkarni VM, Mancini MB, et al. Resuscitation education science: educational strategies to improve outcomes from cardiac arrest: a scientific statement from the American Heart Association. Circulation 2018;138(6):e82-122.

16. Dube MM, Reid J, Kaba A, et al. PEARLS for systems integration: a Modified PEARLS framework for debriefing systems-focused simulations. Simul Healthc 2019;14(5):333-42.

17. Hayes CW, Rhee A, Detsky ME, et al. Residents feel unprepared and unsupervised as leaders of cardiac arrest teams in teaching hospitals: a survey of internal medicine residents. Crit Care Med 2007;35(7):1668-72.

18. Zinns LE, O'Connell KJ, Mullan PC, et al. National survey of pediatric emergency medicine fellows on debriefing after medical resuscitations. Pediatr Emerg Care 2015;31(8):551-4.

19. Couper K, Perkins GD. Debriefing after resuscitation. Curr Opin Crit Care 2013; 19(3):188-94.

20. Kessler DO, Cheng A, Mullan PC. Debriefing in the emergency department after clinical events: a practical guide. Ann Emerg Med 2015;65(6):690-8.

21. Sawyer T, Eppich W, Brett-Fleegler M, et al. More than one way to debrief: a critical review of healthcare simulation debriefing methods. Simul Healthc 2016; 11(3):209-17.

22. Conley DM, Singer SJ, Edmondson L, et al. Effective surgical safety checklist implementation. J Am Coll Surg 2011;212(5):873-9.

23. Alidina S, Goldhaber-Fiebert SN, Hannenberg AA, et al. Factors associated with the use of cognitive aids in operating room crises: a cross-sectional study of US hospitals and ambulatory surgical centers. Implement Sci 2018;13(1):50.

24. Agarwala AV, McRichards LK, Rao V, et al. Bringing perioperative emergency manuals to your institution: a "how to" from concept to implementation in 10 steps. Jt Comm J Qual Patient Saf 2019;45(3):170-9.

25. Braithwaite J, Marks D, Taylor N. Harnessing implementation science to improve care quality and patient safety: a systematic review of targeted literature. Int J Qual Health Care 2014;26(3):321-9.

26. Rapport F, Clay-Williams R, Churruca K, et al. The struggle of translating science into action: foundational concepts of implementation science. J Eval Clin Pract 2018;24(1):117-26.

27. Salas E, Klein C, King H, et al. Debriefing medical teams: 12 evidence-based best practices and tips. Jt Comm J Qual Patient Saf 2008;34(9):518-27. 
28. Voyer S, Hatala R. Debriefing and feedback: two sides of the same coin? Simul Healthc 2015;10(2):67-8.

29. van de Ridder JM, Stokking KM, McGaghie WC, et al. What is feedback in clinical education? Med Educ 2008;42(2):189-97.

30. Raemer D, Anderson M, Cheng A, et al. Research regarding debriefing as part of the learning process. Simul Healthc 2011;6(Suppl):S52-7.

31. Cheng A, Eppich W, Grant V, et al. Debriefing for technology-enhanced simulation: a systematic review and meta-analysis. Med Educ 2014;48(7):657-66.

32. Bowers C, Braun CC, Morgan BB. Team workload: its meaning and measurement. In: Brannick MT, Salas E, Prince C, editors. Team performance assessment and measurement: theory, methods, and applications. Mahwah (NJ): Lawrence Erlbaum Associates; 1997. p. 85-108.

33. Rose MR, Rose KM. Use of a surgical debriefing checklist to achieve higher value health care. Am J Med Qual 2018;33(5):514-22.

34. Haynes AB, Weiser TG, Berry WR, et al. A surgical safety checklist to reduce morbidity and mortality in a global population. N Engl J Med 2009;360(5):491-9.

35. van Klei WA, Hoff RG, van Aarnhem EE, et al. Effects of the introduction of the WHO "Surgical Safety Checklist" on in-hospital mortality: a cohort study. Ann Surg 2012;255(1):44-9.

36. Wolf FA, Way LW, Stewart L. The efficacy of medical team training: improved team performance and decreased operating room delays: a detailed analysis of 4863 cases. Ann Surg 2010;252(3):477-83 [discussion: 483-5].

37. Gillespie BM, Chaboyer W, Thalib L, et al. Effect of using a safety checklist on patient complications after surgery: a systematic review and meta-analysis. Anesthesiology 2014;120(6):1380-9.

38. Leape LL. The checklist conundrum. N Engl J Med 2014;370(11):1063-4.

39. Mitchell JT. When disaster strikes...the critical incident stress debriefing process. JEMS 1983;8(1):36-9.

40. Mitchell AM, Sakraida TJ, Kameg K. Critical incident stress debriefing: implications for best practice. Disaster Manag Response 2003;1(2):46-51.

41. Tavares W, Eppich W, Cheng A, et al. Learning conversations: an analysis of the theoretical roots and their manifestations of feedback and debriefing in medical education. Acad Med 2019;95(7):1020-5.

42. Eppich WJ, Hunt EA, Duval-Arnould JM, et al. Structuring feedback and debriefing to achieve mastery learning goals. Acad Med 2015;90(11):1501-8.

43. Eppich W, Cheng A. Promoting Excellence and Reflective Learning in Simulation (PEARLS): development and rationale for a blended approach to health care simulation debriefing. Simul Healthc 2015;10(2):106-15.

44. Bajaj K, Meguerdichian M, Thoma B, et al. The PEARLS Healthcare Debriefing Tool. Acad Med 2018;93(2):336.

45. Arriaga AF, Gawande AA, Raemer DB, et al. Pilot testing of a model for insurerdriven, large-scale multicenter simulation training for operating room teams. Ann Surg 2014;259(3):403-10.

46. Fanning RM, Gaba DM. The role of debriefing in simulation-based learning. Simul Healthc 2007;2(2):115-25.

47. Hollnagel E, Wears RL, Braithwaite J. From Safety-I to Safety-II: a White Paper. The Resilient Health Care Net: Published simultaneously by the University of Southern Denmark, University of Florida, USA, and Macquarie University, Australia. Available at: https://www.england.nhs.uk/signuptosafety/wp-content/ uploads/sites/16/2015/10/safety-1-safety-2-whte-papr.pdf. Accessed May 30, 2020. 
48. Tucker AL, Edmondson AC. Why hospitals don't learn from failures: organizational and psychological dynamics that inhibit system change. Calif Manag Rev 2003;45(2):55-72.

49. Brindle ME, Henrich N, Foster A, et al. Implementation of surgical debriefing programs in large health systems: an exploratory qualitative analysis. BMC Health Serv Res 2018;18(1):210.

50. Todesco J, Rasic NF, Capstick J. The effect of unanticipated perioperative death on anesthesiologists. Can J Anaesth 2010;57(4):361-7.

51. Dzau VJ, Kirch DG, Nasca TJ. To Care Is Human - Collectively Confronting the Clinician-Burnout Crisis. N Engl J Med 2018;378(4):312-4.

52. Shanafelt TD, Dyrbye LN, West CP. Addressing physician burnout: the way forward. JAMA 2017;317(9):901-2.

53. Thomas LR, Ripp JA, West CP. Charter on physician well-being. JAMA 2018; 319(15):1541-2.

54. Hu YY, Arriaga AF, Roth EM, et al. Protecting patients from an unsafe system: the etiology and recovery of intraoperative deviations in care. Ann Surg 2012;256(2): 203-10.

55. Reason JT. The human contribution: unsafe acts, accidents and heroic recoveries. Burlington (VT): Ashgate; 2008.

56. Kagee A. Concerns about the effectiveness of critical incident stress debriefing in ameliorating stress reactions. Crit Care 2002;6(1):88.

57. Mullan PC, Wuestner E, Kerr TD, et al. Implementation of an in situ qualitative debriefing tool for resuscitations. Resuscitation 2013;84(7):946-51.

58. Sandhu N, Eppich W, Mikrogianakis A, et al. Postresuscitation debriefing in the pediatric emergency department: a national needs assessment. CJEM 2014; 16(5):383-92.

59. Pittman J, Turner B, Gabbott DA. Communication between members of the cardiac arrest team-a postal survey. Resuscitation 2001;49(2):175-7.

60. Sweeney RE, Clapp JT, Arriaga AF, et al. Understanding debriefing: a qualitative study of event reconstruction at an academic medical center. Acad Med 2019; 95(7):1089-97.

61. Rudolph JW, Simon R, Raemer DB, et al. Debriefing as formative assessment: closing performance gaps in medical education. Acad Emerg Med 2008; 15(11):1010-6.

62. Pian-Smith MCM, Cooper JB. If we don't learn from our critical events, we're likely to relive them: debriefing should be the norm. Anesthesiology 2019;130(6): 867-9.

63. Rabin BA, Brownson RC, Haire-Joshu D, et al. A glossary for dissemination and implementation research in health. J Public Health Manag Pract 2008;14(2): $117-23$.

64. Brownson RC, Fielding JE, Maylahn CM. Evidence-based public health: a fundamental concept for public health practice. Annu Rev Public Health 2009;30: 175-201.

65. Palinkas LA, Aarons GA, Horwitz S, et al. Mixed method designs in implementation research. Adm Policy Ment Health 2011;38(1):44-53.

66. Kirchner JE, Smith JL, Powell BJ, et al. Getting a clinical innovation into practice: an introduction to implementation strategies. Psychiatry Res 2020;283:112467.

67. Greenhalgh T, Robert G, Macfarlane F, et al. Diffusion of innovations in service organizations: systematic review and recommendations. Milbank Q 2004;82(4): 581-629. 
68. Powell BJ, Waltz TJ, Chinman MJ, et al. A refined compilation of implementation strategies: results from the Expert Recommendations for Implementing Change (ERIC) project. Implement Sci 2015;10:21.

69. Damschroder LJ, Aron DC, Keith RE, et al. Fostering implementation of health services research findings into practice: a consolidated framework for advancing implementation science. Implement Sci 2009;4:50.

70. Meyers DC, Durlak JA, Wandersman A. The quality implementation framework: a synthesis of critical steps in the implementation process. Am J Community Psychol 2012;50(3-4):462-80.

71. Gagliardi AR, Marshall C, Huckson S, et al. Developing a checklist for guideline implementation planning: review and synthesis of guideline development and implementation advice. Implement Sci 2015;10:19.

72. Gillespie BM, Marshall A. Implementation of safety checklists in surgery: a realist synthesis of evidence. Implement Sci 2015;10:137.

73. Gaba DM, Fish KJ, Howard SK, et al. Crisis management in anesthesiology. Second edition. Philadelphia: Elsevier/Saunders; 2015.

74. Runciman WB, Webb RK, Klepper ID, et al. The Australian Incident Monitoring Study. Crisis management-validation of an algorithm by analysis of 2000 incident reports. Anaesth Intensive Care 1993;21(5):579-92.

75. Link MS, Berkow LC, Kudenchuk PJ, et al. Part 7: adult advanced cardiovascular life support: 2015 American Heart Association Guidelines Update for Cardiopulmonary Resuscitation and Emergency Cardiovascular Care. Circulation 2015; 132(18 Suppl 2):S444-64.

76. Moitra VK, Einav S, Thies KC, et al. Cardiac arrest in the operating room: resuscitation and management for the anesthesiologist: part 1. Anesth Analg 2018; 126(3):876-88.

77. Runciman WB, Merry AF. Crises in clinical care: an approach to management. Qual Saf Health Care 2005;14(3):156-63.

78. Hepner DL, Arriaga AF, Cooper JB, et al. Operating Room Crisis Checklists and Emergency Manuals. Anesthesiology 2017;127(2):384-92.

79. Stanford Anesthesia Cognitive Aid Group*. Emergency manual: cognitive aids for perioperative clinical events. Available at: http://emergencymanual.stanford.edu for latest version. Creative Commons BY-NC-ND. 2013 (creativecommons.org/licenses/by-nc-nd/3.0/legalcode). ${ }^{\star}$ Core contributors in random order: Howard SK, Chu LK, Goldhaber-Fiebert SN, Gaba DM, Harrison TK.

80. Goldhaber-Fiebert SN, Howard SK. Implementing emergency manuals: can cognitive aids help translate best practices for patient care during acute events? Anesth Analg 2013;117(5):1149-61.

81. Arriaga AF, Bader AM, Wong JM, et al. Simulation-based trial of surgical-crisis checklists. N Engl J Med 2013;368(3):246-53.

82. Emergency Manuals Implementation Collaborative. Available at: https://www. emergencymanuals.org. Accessed April 10, 2020.

83. Hannenberg AA. Cognitive aids in the management of critical events. Anesthesiol Clin 2020;38(4):789-800.

84. The Operating Room Emergency Checklist Implementation Toolkit. Available at: https://www.implementingemergencychecklists.org/. Accessed April 10, 2020.

85. Bardes JM, Biswas S, Strumwasser AM, et al. Comparison of trauma resuscitation practices by critical care anesthesiologists and non-critical care anesthesiologists. J Clin Anesth 2020;65:109890. 
86. Arriaga AF, Elbardissi AW, Regenbogen SE, et al. A policy-based intervention for the reduction of communication breakdowns in inpatient surgical care: results from a Harvard surgical safety collaborative. Ann Surg 2011;253(5):849-54.

87. Lingard L, Espin S, Whyte S, et al. Communication failures in the operating room: an observational classification of recurrent types and effects. Qual Saf Health Care 2004;13(5):330-4.

88. Hu YY, Arriaga AF, Peyre SE, et al. Deconstructing intraoperative communication failures. J Surg Res 2012;177(1):37-42.

89. Greenberg CC, Regenbogen SE, Studdert DM, et al. Patterns of communication breakdowns resulting in injury to surgical patients. J Am Coll Surg 2007;204(4): 533-40.

90. Bacon AK, Morris RW, Runciman WB, et al. Crisis management during anaesthesia: recovering from a crisis. Qual Saf Health Care 2005;14(3):e25.

91. Rudolph JW, Simon R, Dufresne RL, et al. There's no such thing as "nonjudgmental" debriefing: a theory and method for debriefing with good judgment. Simul Healthc 2006;1(1):49-55.

92. Center for Medical Simulation. Available at: https://harvardmedsim.org/. Accessed April 11, 2020.

93. Delisle M, Hannenberg AA. Alternatives to high-fidelity simulation. Anesthesiol Clin 2020;38(4):761-73.

94. Cheng A, Eppich W, Kolbe M, et al. A conceptual framework for the development of debriefing skills: a journey of discovery, growth, and maturity. Simul Healthc 2020;15(1):55-60.

95. PEARLS Healthcare Debriefing Tool. Available at: https://debrief2learn.org/ pearls-debriefing-tool/. Accessed April 11, 2020.

96. Rose $S$, Cheng A. Charge nurse facilitated clinical debriefing in the emergency department. CJEM 2018;20(5):781-5.

97. Cheng A, Grant V, Huffman J, et al. Coaching the debriefer: peer coaching to improve debriefing quality in simulation programs. Simul Healthc 2017;12(5): 319-25.

98. Wyckoff MH, Aziz K, Escobedo MB, et al. Part 13: neonatal resuscitation: 2015 American Heart Association guidelines update for cardiopulmonary resuscitation and emergency cardiovascular care. Circulation 2015;132(18 Suppl 2): S543-60. 